\title{
Metaética de la Corte Suprema de Justicia de la Nación Argentina en la jurisprudencia de la dosis personal
}

\author{
Ariel Fernando Rincón Almeyda*
}

* Doctor (c) en Derecho, Universidad de Buenos Aires, Buenos Aires, Argentina. Docente Cátedra, Universidad Industrial de Santander (UIS), Bucaramanga, Colombia.. Correo electrónico: dcderecho@unicienciabga.edu.co

Recibido: 5 de marzo de 2014

Aprobado: 5 de mayo de 2014

Cómo citar este artículo:

Ariel Fernando Rincón Almeyda. Metaética de la Corte Suprema de Justicia Argentina en la jurisprudencia de la dosis personal. DIXI. Junio 2014. Pág. 37. doi: http://dx.doi. org/10.16925/di.v16i19.730

\section{Resumen}

El presente artículo tiene como finalidad determinar que las decisiones de las supremas cortes, sin importar la latitud, dependen del sistema filosófico del operador jurídico. Esta idea supera la concepción de que el sistema normativo determina el resultado jurídico y aspira consolidar la idea de que el operador jurídico toma una decisión de política jurídica. El marco jurisprudencial argentino no es más que una excusa, pues, en estricto sentido, si se hace un análisis metaético a cualquier corte suprema, tendremos como resultado la discrecionalidad judicial.

Palabras clave: argumentación jurídica metaética, filosofía del derecho, línea jurisprudencial.

Meta-ethics of the Supreme Court of Justice of the Argentine Nation in Jurisprudence Regarding the Personal Dose

\section{Abstract}

This article seeks to show that decisions by Supreme Courts, regardless of the latitude, depend upon the philosophical system of the legal operator. This idea goes beyond the concept that the normative system determines the legal result and seeks instead to establish the idea that legal operators make legal policy decisions. The Argentine jurisprudential framework is nothing more than an excuse, because, in the strictest sense, if a meta-ethical analysis is made of any Supreme Court, the result will point to judicial discretion.

Keywords: meta-ethical argumentation, philosophy of the law, jurisprudential line.

Metaética da Suprema Corte de Justiça da NaÇão Argentina na jurisprudênCia da dose PESSOAL

Resumo

O presente artigo tem como objetivo determinar que as decisões das supremas cortes, sem importar a latitude, dependem do sistema filosófico do operador jurídico. Essa ideia supera a concepção de que o sistema normativo determina o resultado jurídico e aspira consolidar a ideia de que o operador jurídico toma uma decisão de política jurídica. Portanto, o marco jurisprudencial argentino não é mais que uma desculpa, já que, se for feita uma análise metaética a qualquer suprema corte, teremos como resultado a discricionariedade judicial.

Palavras-chave: argumentação jurídica metaética, filosofia do direito, linha jurisprudencial. 


\section{INTRODUCCIÓN ${ }^{1}$}

La construcción del objeto de estudio del derecho siempre ha estado determinada por tensiones de tres elementos: normas, valores y conductas. A partir de estas tensiones, se han edificado diversas teorías, unas que ponen principal énfasis en las normas, otras en los valores y otras en las conductas. Es más, se han planteado teorías que pretenden integrar estos elementos. Las posibilidades de integración pueden ser bidimensionales, en el sentido de que integran dos elementos, o tridimensionales, cuando la pretensión ha sido integrar los tres elementos. ${ }^{2}$

Pese a los grandes esfuerzos de las corrientes integracionistas por intentar entender el objeto de estudio de una forma integral, la tensión de estos tres elementos, o dos, hace que en última instancia se termine poniendo énfasis en uno de ellos. Kelsen entendía esto y, en tal sentido, edificó el objeto del derecho basado en las normas o, para ser más preciso, en el orden normativo entendido como una pirámide. Frente al cuestionamiento de las conductas y los valores, estableció que el juez, en últimas, lo que hace es tomar una decisión política dentro de un marco de posibilidades y, en el evento de tomar una decisión contraria a una norma en concreto, se debe a la regla de habilitación. ${ }^{3}$

Esta premisa de la habilitación permite que un juez en un momento histórico determinado cambie los alcances de una norma jurídica. Es decir que interprete la misma norma jurídica, en casos cuyas condiciones fácticas son similares, con efectos diferentes. Este es el caso, por ejemplo, de la jurisprudencia sobre tenencia destinada al consumo personal de estupefacientes o, como se conoce popularmente, dosis personal.

Ahora bien, importa para los efectos del presente artículo tratar de determinar no tanto las razones que se esgrimen para el cambio de jurisprudencia, pues, independientemente de las que sean, el sistema jurí-

1. Producto de la investigación Teoría trialista de la conciliación, realizada en la Universidad de Buenos Aires.

2. Esta forma de clasificar las teorías jurídicas ha sido desarrollada principalmente por aquellos autores que aspiran a la integración de estos tres elementos para construir el objeto de estudio. Véase Werner Goldschmidt. Introducción filosófica al Derecho. 7. ${ }^{a}$ ed. Lexis Nexis. (2005).

3. Hans Kelsen. Teoría PURA Del derecho. 18. ${ }^{a}$ ed. Trad. Moisés Nilve. Editorial UBA. (1982). dico valida esta actuación, sino los fundamentos axiológicos de la decisión.

Frente al reciente cambio de jurisprudencia de la Corte Suprema de Justicia, en la tenencia de estupefacientes destinada al consumo personal, podría interpretarse que hubo un cambio en la metaética de la decisión. Sin embargo, el estudio de la línea jurisprudencial del referido tema nos conduce a concluir que hubo una modificación en el valor que sustenta la decisión, mas no en el fundamento del valor.

Para sostener esta idea, me permito construir el presente artículo en tres etapas: fundamentos teóricos de la metaética, línea jurisprudencial de la tenencia de estupefacientes destinados al consumo personal y análisis de la línea jurisprudencial a la luz de los fundamentos metaéticos.

\section{Fundamentos TEÓRICOS DE LA METAÉTICA}

Los fundamentos teóricos de la metaética los planteo desde la clasificación propuesta por el profesor Eduardo Barbarosch, ${ }^{4}$ quien considera la existencia de dos corrientes básicas del pensamiento metaético: una de corte escéptica, ${ }^{5}$ proyectivismo moral, y otra de estirpe objetiva, realismo moral.

\section{A. Concepción metaética de corte escéptica}

El escepticismo como forma de entender el tema axiológico fue desarrollado por Hume, quien parte de la inexistencia de los valores. Para este pensador, toda creencia que se refiera al mundo tiene por función representarlo tal y como es. Una teoría será satisfactoria o válida en la medida que logre representarlo y, por tanto, determinar su verdad o falsedad. Es decir, que una teoría es verdadera en la medida que represente al mundo, mientras que será falsa en la medida que fracase en su intento.

Basado en esta idea, Mackie desarrolla su teoría del error. Con ella pretende demostrar que las con-

\footnotetext{
4. Eduardo Barbarosch. TEORÍAS DE LA JUSTICIA Y LA METAÉTICA CONTEMPoránea. Facultad de Derecho de la UBA y La Ley. (2007).

5. En principio, pudiera pensarse que no es posible hablar de valores desde una perspectiva escéptica porque se caen en su peso, sin embargo la tesis del autor sostiene que si es posible siempre y cuando partamos de un consenso unánime. En este sentido, demuestra que la teoría de la justicia de John Rawls se fundamenta en cierto escepticismo moral.
} 
cepciones objetivistas de los valores son falsas porque caen en alguno de los siguientes cinco errores: ${ }^{6}$

- La variabilidad de importantes puntos de vista morales en relación con ciertas formas de vida. Esto es que el punto de vista moral o los valores cambian de acuerdo con las condiciones humanas de existencia.

- La pluralidad metafísica que supone afirmar la objetividad de los valores que per se son guía de las acciones.

- Los valores pueden ser supervenientes de ciertos rasgos naturales.

- La dificultad epistemológica que supone explicar cómo se produce el conocimiento de tales entidades valorativas y su conexión con las cosas de las cuales aquellas serían su consecuencia.

- La posibilidad de explicar a través del lenguaje moral objetivizado cuando en realidad no existen tales valores objetivos.

Con esta teoría de los errores, el profesor Barbarosch propone identificar las concepciones del realismo moral. Toda concepción que lleve implícita alguno de estos elementos o errores es una teoría realista. Por el contrario, una concepción que abandone o supere estos errores se edifica como proyectivista moral.

Esta forma o método para abordar el tema nos invita a identificar una concepción axiológica de forma diferente de la planteada tradicionalmente. El planteamiento clásico nos invita a definir una serie de categorías y verificar cómo se despliegan en una concepción. El método planteado nos invita a lo contrario, es decir, a la verificación que no se desarrollen determinadas categorías. Es una forma de construir desde la negación.

\section{B. Concepción metaética de estirpe objetiva}

Esta corriente del pensamiento valorativo considera que los valores tienen existencia propia. Esto es que tanto las acciones como los objetos tienen un valor propio y que el ser humano cuando se acerca a ellos lo que hace es descubrirlos. En este sentido, "el valor de un estado de cosas o de una acción no depende

6. Véase Barbarosch, supra, nota 4. Pág. 3. en absoluto de que algún agente en el mundo se lo atribuya". ${ }^{7}$

Dentro de los seguidores de esta concepción, podemos ubicar a Goldschmidt. Para este jurista el mundo o universo está forma por objetos materiales en sí y por entes ideales. Los entes ideales tienen vida propia y el hombre lo que hace es acercarse a ellos a través de la razón. ${ }^{8}$ Goldschmidt considera que el valor absoluto que debe orientar las acciones de los hombres está constituido por el principio de justicia que consiste en otorgar a cada individuo un escenario de libertad tal que le permita personalizarse.

El autor, partiendo de su concepción metaéti$\mathrm{ca}$, propone que existen tres medios para lograr este principio supremo: protección del individuo contra los demás, protección del individuo por otras circunstancias y protección del individuo contra sí mismo. $^{9}$

\section{LÍNEA JURISPRUDENCIAL DE LA TENENCIA DE ESTUPEFACIENTES DESTINADOS AL CONSUMO PERSONAL}

La línea jurisprudencial definida por la Corte Suprema de Justicia es posible representarla en la tabla 1.

La línea jurisprudencial expuesta en la tabla 1 nos ayuda a identificar los pronunciamientos de la Corte Suprema de Justicia respecto del tema propuesto. La metodología del esquema consiste en ubicar espacialmente las normas ${ }^{10}$ según si permiten o no la tenencia de estupefacientes destinados al consumo personal.

7. Juan Carlos Bayón Mohino. La NORMATIVIDAd DEL DERECHO: DEber JURÍDICO Y RAZONES PARA LA ACCIÓN. Citado por Barbarosch, supra, nota 4. Pág. 21.

8. Para edificar su objetivismo valorativo asume las ideas de Tomás de Aquino, quien sostiene que existen cuatro clases de leyes: eterna, natural, divina y humana. La ley eterna es aquella que solo conoce Dios, pues consiste en la divina sabiduría que dirige lo que ocurre en el universo; aunque el hombre no pueda acceder a la ley eterna sí puede participar en ella de algún modo a través de la razón, ley natural (consiste en una serie de principios generales y abstractos); dado el carácter abstracto de la ley natural se edifica la ley divina, compuesta por las Sagradas Escrituras; y la ley humana como un acto del poder del soberano fundado en la razón, la cual "si contradice algún principio fundamental de justicia no será ley, sino una perversión de la ley”. Véase Edgar Bodenheimmer. TeORÍA DEL Derecho. 7. a ed. Trad. Vicente Herrero. Págs. 145-149. Fondo de Cultura Económico. (1979).

9. Véase Goldschmidt, supra, nota 2.

10. El concepto de norma lo asumo atendiendo a la clasificación de las normas generales y normas particulares. De las primeras dan cuenta las leyes, mientras que de las segundas las sentencias. 
Tabla 1. Línea jurisprudencial de la tenencia de estupefacientes destinados al consumo personal

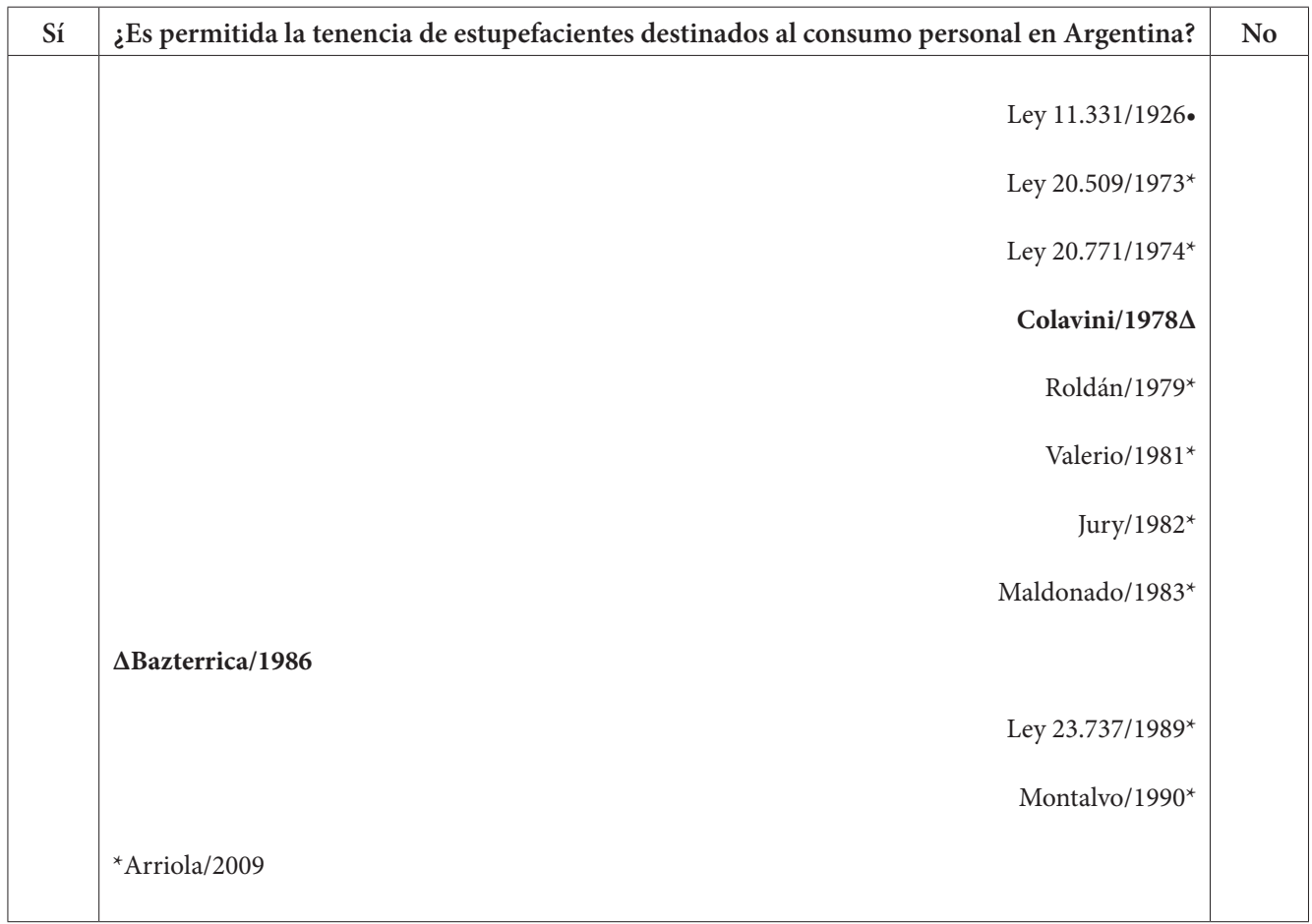

Fuente: elaboración propia

Las normas que se ubican en el extremo "Sí" permiten la tenencia de estupefacientes para el consumo personal; las que se ubican en el extremo "No" niegan la posibilidad de tenencia de estupefacientes con destino al consumo personal; la norma que se ubica en una posición intermedia, pero tendiente al extremo "No" de la tabla, explica la prohibición general de la tenencia de estupefacientes destinados al consumo personal, pero la permiten en algunas circunstancias.

Las normas identificadas con el símbolo • constituyen aquellas normas fundadoras de línea, es decir, aquellas que definieron el tema en alguna de las posibilidades interpretativas; las normas identificadas con el símbolo $\Delta$ identifican a la sentencia hito, es decir, aquel pronunciamiento que va siendo reiterado y que se tiene como fuente de decisiones posteriores, y finalmente las normas identificadas con el símbolo * identifican las normas confirmadoras de línea, es decir, aquellas que ratifican los criterios establecidos por una norma anterior.
La norma que da surgimiento a la línea jurisprudencial es la Ley 11.331 de 1926. La primera norma prohíbe y penaliza la tenencia de estupefacientes destinados al consumo personal, pero estableciendo la excepción de caso clínico. Con ello permite la tenencia, pero solo cuando se requieran por un tratamiento clínico. ${ }^{11}$

Las sentencias hito adquieren vital importancia porque ellas son las que definen criterios teóricos y asumen una posición respecto del tema. Por su cuenta, las sentencias confirmadoras de línea tienden a reafirmar la sentencia y, en algunos casos, ampliar el radio argumentativo. En este sentido, se hace necesario establecer los argumentos diferenciadores de las sentencias, que nos permitan acercarnos a la metaética de cada una de estas decisiones.

11. Un análisis contextualizado de la presente línea nos llevaría a la construcción de conjeturas respecto a las tensiones sociales que suscita el tema, especialmente en momentos históricos, sin embargo las pretensiones del presente escrito están orientadas en el sentido de la verificación metaética de las normas. 
Tabla 2. Comparación de las principales de la Corte Suprema de Justicia

\begin{tabular}{|c|c|c|c|c|}
\hline & Colavini (1978) & Bazterrica (1986) & Montalvo (1990) & Arriola (2009) \\
\hline Decisión & $\begin{array}{l}\text { Prohibir la tenencia de } \\
\text { estupefacientes destinados } \\
\text { al consumo personal. }\end{array}$ & $\begin{array}{l}\text { Permitir la tenencia de } \\
\text { estupefacientes destinados } \\
\text { al consumo personal. }\end{array}$ & $\begin{array}{l}\text { Prohibir la tenencia de } \\
\text { estupefacientes destinados } \\
\text { al consumo personal. }\end{array}$ & $\begin{array}{l}\text { Permitir la tenencia de estupefacien- } \\
\text { tes destinados al consumo personal. }\end{array}$ \\
\hline Fundamentos & $\begin{array}{l}\text { 1. Ley } 20.771 / 1974 \\
\text { 2. Ley } 21.422 \text { que incorpo- } \\
\text { ra el Acuerdo Sudamerica- } \\
\text { no sobre Estupefacientes y } \\
\text { Sicotrópicos. }\end{array}$ & $\begin{array}{l}\text { 1. Artículo } 19 \text { de la Consti- } \\
\text { tución Nacional. } \\
\text { 2. Informe } 18 \text { del Comité } \\
\text { de Expertos de la Organi- } \\
\text { zación Mundial de la Salud } \\
\text { (OMS). } \\
\text { 3. Conclusiones del Grupo } \\
\text { de Estudios de la OMS } \\
\text { sobre la Juventud y Drogas. } \\
\text { 4. Quinto Congreso de las } \\
\text { Naciones Unidas sobre } \\
\text { Prevención del Delito y } \\
\text { Tratamiento del Delin- } \\
\text { cuente. } \\
\text { 5. Instituto de Investigacio- } \\
\text { nes de las Naciones Unidas } \\
\text { para la Defensa Social. } \\
\text { 6. El Decreto-Ley } \\
7672 / 1963 \text { incorpora la } \\
\text { Convención Única sobre } \\
\text { Estupefacientes de 1961. }\end{array}$ & $\begin{array}{l}\text { 1. Ley } 20.771 / 1974 . \\
\text { 2. Ley } 23.737 / 1989 . \\
\text { 3. Debate en Cámara de } \\
\text { Representantes de la Ley } \\
23.737 / 1989 . \\
\text { 4. Debate en Senado de la } \\
\text { Ley } 23.737 / 1989 . \\
\text { 5. Colavini (1978). }\end{array}$ & 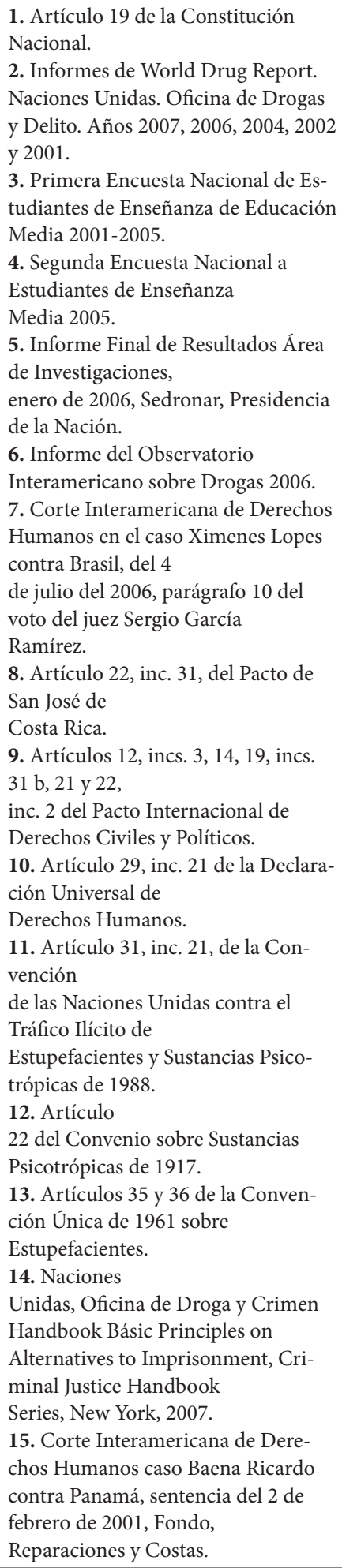 \\
\hline
\end{tabular}




\begin{tabular}{|c|c|c|c|c|}
\hline $\begin{array}{l}\text { Razones } \\
\text { alegadas }\end{array}$ & $\begin{array}{l}\text { 1. El narcotráfico es una } \\
\text { calamidad social compara- } \\
\text { ble con las guerras y no con } \\
\text { las pestes. } \\
\text { 2. La ley pena el tráfico de } \\
\text { estupefacientes, el cual va } \\
\text { desde la producción hasta } \\
\text { el consumo. } \\
\text { 3. Si no existieren usuarios } \\
\text { no habría estimulación a la } \\
\text { producción. } \\
\text { 4. Reconoce que, para la } \\
\text { existencia de un Estado } \\
\text { democrático, se necesita } \\
\text { libertades privadas, pero } \\
\text { que estas no deben ofender } \\
\text { el orden y la moral pública. } \\
\text { 5. El derecho penal solo } \\
\text { debe castigar acciones y } \\
\text { aquellas que perturben el } \\
\text { bien común, es decir, aque- } \\
\text { llas acciones que afecten } \\
\text { el orden y la moralidad } \\
\text { pública o perjudiquen los } \\
\text { derechos de terceros. } \\
\text { 6. Esta conducta individual } \\
\text { sí trasciende la esfera } \\
\text { privada. } \\
\text { 7. La prohibición no infrin- } \\
\text { ge el ámbito de libertad del } \\
\text { individuo. } \\
\text { 8. El consumo está en la } \\
\text { órbita pública. } \\
\text { 9. Hay un consenso im- } \\
\text { perante de los gravísimos } \\
\text { efectos tanto de índole físi- } \\
\text { ca como psíquica, entonces } \\
\text { se debe salvaguardar la } \\
\text { salud pública. } \\
\text { 10. Tiende a destruir la } \\
\text { familia, la cual es el núcleo } \\
\text { esencial de la sociedad. }\end{array}$ & 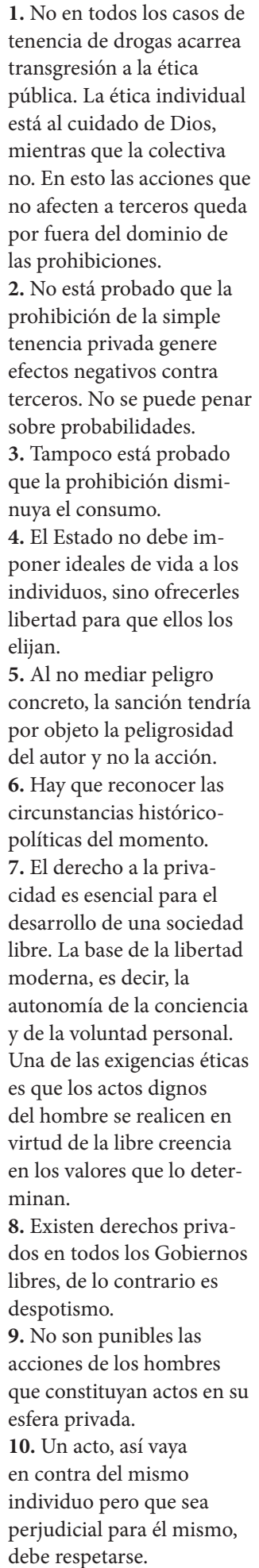 & $\begin{array}{l}\text { 1. Proteger a la comunidad } \\
\text { contra un azote de la salud } \\
\text { humana. Se reprime es el } \\
\text { delito contra la salud públi- } \\
\text { ca y lo que va en contra del } \\
\text { interés general que está por } \\
\text { encima del individuo. } \\
\text { 2. La Corte no puede in- } \\
\text { tervenir en circunstancias } \\
\text { de mérito y conveniencia } \\
\text { salvo que los medios para } \\
\text { alcanzar los fines no sean } \\
\text { idóneos. } \\
\text { 3. La drogadicción genera } \\
\text { un efecto contagioso y sus } \\
\text { acciones no quedan en lo } \\
\text { privado sino que se extien- } \\
\text { den a lo público. } \\
\text { 4. Detrás del tenedor está el } \\
\text { vendedor. } \\
\text { 5. Este delito tiende a pro- } \\
\text { teger intereses colectivos } \\
\text { y, por tanto, a la familia, } \\
\text { la juventud y al mismo } \\
\text { individuo. El Estado no se } \\
\text { puede abstraer de proteger } \\
\text { al mismo individuo. } \\
\text { 6. Es una conducta de } \\
\text { peligro abstracto. } \\
\text { 7. La tipificación conduce } \\
\text { a reprimir todas las con- } \\
\text { ductas relacionadas con } \\
\text { el narcotráfico, pues este } \\
\text { atenta contra la existencia } \\
\text { misma del Estado y de las } \\
\text { instituciones. } \\
\text { 8. Es un mandato clamo- } \\
\text { roso de la comunidad que } \\
\text { quiere terminar con el } \\
\text { flagelo. } \\
\text { 9. Con la sentencia Bazte- } \\
\text { rrica proliferó el consumo. }\end{array}$ & $\begin{array}{l}\text { 1. Ciertas normas susceptibles de } \\
\text { ser consideradas legítimas en su } \\
\text { origen pudieron haberse tornado } \\
\text { indefendibles desde el punto de vista } \\
\text { constitucional con el transcurso del } \\
\text { tiempo y el cambio de circunstancias } \\
\text { objetivas relacionadas con ellas. } \\
\text { 2. Las razones pragmáticas o utilita- } \\
\text { ristas de "Montalvo" han fracasado. } \\
\text { En efecto, allí se había sostenido que } \\
\text { la incriminación del tenedor de estu- } \\
\text { pefacientes permitiría combatir más } \\
\text { fácilmente a las actividades vincula- } \\
\text { das con el comercio de estupefacien- } \\
\text { tes, lo cual no se ha cumplido. } \\
\text { 3. El país ocupa el segundo lugar de } \\
\text { Sudamérica en } \\
\text { consumo de cocaína. } \\
\text { 4. Aumento del consumo. } \\
\text { 5. El debate jurídico plasmado en } \\
\text { "Bazterrica" "Montalvo" } \\
\text { se ha llevado a cabo con anterioridad } \\
\text { a la reforma } \\
\text { Constitucional de 1994, lo cual cam- } \\
\text { bia el panorama constitucional. } \\
\text { 6. Con esta sentencia se protege el } \\
\text { derecho a la privacidad que impide } \\
\text { que las personas sean objeto de } \\
\text { injerencias arbitrarias o abusivas } \\
\text { en su vida privada. El principio de } \\
\text { dignidad que consagra al hombre } \\
\text { como un fin en sí mismo se opone a } \\
\text { que sea tratado utilitariamente sujeto } \\
\text { a las iniciativas y cuidados del poder } \\
\text { público. } \\
\text { 7. Un Estado no puede juzgar la } \\
\text { existencia misma de la persona, su } \\
\text { proyecto de vida y su realización. } \\
\text { 8. De ninguna manera podrían in- } \\
\text { vocarse el "orden público" o el "bien } \\
\text { común" como medios para suprimir } \\
\text { derechos. } \\
\text { 9. El Estado debe preparar su aparato } \\
\text { de salud pública, asistencia y educa- } \\
\text { ción, de modo que asegure que los } \\
\text { adictos puedan recibir tratamientos } \\
\text { médicos. } \\
\text { 10. La Ley } 23.737 \text { sólo se aplica en las } \\
\text { penas y no en la alternatividad penal. } \\
\text { 11. El Estado tiene el deber de tratar } \\
\text { a todos sus habitantes con igual con- } \\
\text { sideración y respeto. La preferencia } \\
\text { general de la gente por una política } \\
\text { no puede reemplazar las preferencias } \\
\text { personales de un individuo. }\end{array}$ \\
\hline
\end{tabular}

Fuente: elaboración propia 


\section{LÍNEA JURISPRUDENCIAL A LA LUZ DE} LOS FUNDAMENTOS METAÉTICOS

Respecto del contenido de las sentencias que hacen a la línea jurisprudencial, es posible por lo menos formular dos líneas de análisis: una referida a los fundamentos de las razones y otra a las razones mismas. El primer tipo de análisis nos conduce, necesariamente, a la discusión de las fuentes del derecho; mientras que el segundo tipo de análisis, a la metaética de las razones.

El primer tipo de análisis no se abordará, basta con observar que, sin importar la decisión que se tome, la Corte fundamenta sus decisiones en normas del sistema jurídico. Esta observación reafirma (la idea inicial de este escrito) que la operatividad del sistema jurídico se garantiza en la medida en que las decisiones se tomen dentro de una marco de posibilidades con su consecuente principio de habilitación, lo cual conduce a ocultar la postura axiológica de la Corte tras el mencionado marco de posibilidades.

En este caso, las decisiones que prohíben la tenencia de estupefacientes se fundamentan en normas de carácter nacional, mientras aquellas que permiten la tenencia de estupefacientes se fundamentan en mayor medida en normas internacionales y la Constitución Política. ${ }^{12}$

\section{CONCLUSIONES}

Dadas estas circunstancias, la metaética de la Corte Suprema no es posible ubicarla en los fundamentos de las sentencias, pues estos solo sirven como mecanismo de blindaje axiológico. La metaética hay que buscarla en las razones.

Un principio de ordenación de las razones expuestas por la Corte consiste en verificar las tensiones que subyacen en cada una de las sentencias y verificar las razones de preferencia del elemento en tensión.

En Colavini, los elementos en tensión son: 1) libertad privada-orden y moral pública, 2) narcotráfico-integridad familiar, 3) daño personal-salud pública y 4) consumidor-cadena económica ilegal.

12. La utilización de una u otra fuente depende en gran medida por la estructura propia de cada uno de los tipos de normas. Mientras que las normas nacionales, específicamente las penales, son concretas y dirigen su estructura al seguimiento, las normas internacionales y constitucionales son abiertas y dirigen su estructura a la interpretación. Las primeras brindan un marco restringido de interpretación, por el contrario, las segundas son eminentemente interpretativas.
La resolución de cada una de estas tensiones es superada poniendo énfasis en una de ellas. Frente a la primera tensión (libertad privada-orden y moral pública) la sentencia se define por entender que la tenencia de estupefacientes destinados al consumo personal no son del resorte de la libertad privada, pues esta trasciende y atenta directamente contra el orden y la moral pública. La segunda tensión es resuelta (narcotráfico-integridad familiar) estableciendo que el narcotráfico es una calamidad comparable a las guerras, lo cual afecta la integridad familiar como núcleo esencial de la comunidad. La tercera tensión (daño personal-salud pública) es superada poniendo énfasis en que el consumo de estupefacientes es un problema de salud pública (el individuo, al hacerse daño a sí mismo, trasciende a la esfera de lo público). La cuarta tensión (consumidor-cadena económica ilegal) está direccionada a entender que el consumidor hace parte de la cadena económica ilegal del narcotráfico (sin consumo no hay oferta).

En Bazterrica, los elementos en tensión se pueden agrupar de la siguiente forma: 1) ética privada-daño a terceros, 2) prohibición-aumento del consumo, 3) moral individual-moral colectiva y 4) peligrosidad-culpabilidad.

La primera tensión definida en Bazterrica (ética privada-daño a terceros) es resuelta entendiendo que el consumo de estupefacientes hace parte de la ética privada y que no está demostrado que esta afecte a terceros. La segunda tensión (prohibición del consumo-aumento del consumo) define que no está demostrado que la prohibición de tenencia de estupefacientes destinados al consumo disminuya su consumo. La tercera tensión (moral individual-moral colectiva) es definida estableciendo que el Estado no puede imponer una moral definida, sino que debe otorgar un escenario de libertad y que cada individuo defina la moral que le parezca. La cuarta tensión (peligrosidad-culpabilidad) se asume definiendo que el sistema penal argentino se fundamenta en las conductas de los hombres y, por tanto, en la responsabilidad de sus actos, mas no en las condiciones personalísimas del individuo.

En Montalvo, las tensiones son las siguientes: 1) daño personal-salud pública, 2) libertad privada-orden y moral pública, 3) consumo personal-interés colectivo, 4) narcotráfico-Estado y 5) prohibición-aumento del consumo.

La primera tensión (daño personal-salud pública) es definida en los mismos términos que en Colavini, estableciendo que el consumo genera dependencia y, por tanto, un problema de salud pública. La segunda tensión (libertad privada-orden y moral pública) 
define que la libertad privada del consumo genera un efecto contagioso y, por tanto, trasciende la esfera de lo privado para convertirse en un problema que afecta el orden y la moral pública. La tercera tensión (consumo personal-interés colectivo) establece que el consumo privado afecta no sólo al individuo, sino a la familia y a la juventud en general. La cuarta tensión (narcotráfico-Estado) establece que el narcotráfico, el cual vincula al consumidor en la cadena económica ilegal, es un flagelo que afecta al Estado y las instituciones poniendo en peligro su existencia. La quinta tensión (prohibición-aumento del consumo) define que la permisión de tenencia hecha en Bazterrica aumentó el consumo.

Las tensiones presentes en Arriola son las siguientes: 1) legitimidad normativa-ilegitimidad normativa, 2) prohibición-aumento del consumo, 3) derecho a la privacidad-interés utilitarista del Estado y 4) delito-salud.

La primera tensión (legitimidad normativa-ilegitimidad normativa) está dirigida a identificar que las normas pueden ser legítimas en su origen, pero que el paso del tiempo las puede tornar ilegítimas. En este mismo sentido, resalta que las anteriores jurisprudencias se edificaron antes de la reforma constitucional de 1994, lo que afecta su contenido y permite un cambio de jurisprudencia. La segunda tensión (prohibiciónaumento del consumo) establece que la prohibición derivada del caso Montalvo no disminuyó el consumo, por el contrario, lo aumentó y no ayudó a combatir el narcotráfico. La tercera tensión (derecho a la privacidad-interés utilitarista del Estado) establece que el derecho a la privacidad es fundamental y no puede suprimirse por razones de interés colectivo. La cuarta tensión (delito-salud) tiende a identificar que la persona que se encuentra en estado de drogadicción no comete un delito, sino que se debe tratar médicamente. Para este efecto resalta que la ley se torna inconstitucional porque solo ha sido aplicada su parte punitiva y no las medidas de protección.

Estas tensiones comprobadas en cada una de las sentencias son verificables en unas y otras. Esto es que las tensiones se repiten, pero los efectos dependen del acento que se les ponga. Pese a la diversidad de tensiones, es posible identificar dos metatensiones presentes en todas las sentencias: derecho individual fundamental-interés colectivo y consumidor- enfermo.

Estas metatensiones están cada una orientadas por un valor supremo. La primera identifica la tensión entre libertad y seguridad. La segunda tensión está mediada por los valores de libertad de contratación y la vida.
Estos valores se establecen en la jurisprudencia de manera dada, es decir, sin que sean construidos de forma racional, lo que implica que se pueda poner acento en cada uno de ellos desplegando efectos sobre el sistema jurídico no previstos. Para la Corte es suficiente dar algunas razones cayendo en el error quinto descrito por Mackie; es decir, que la pluralidad metafísica que supone afirmar la objetividad de los valores que per se son guía de las acciones. Este error es evidente en la línea jurisprudencial, pues simplemente se cambia el valor direccionando comportamientos, dando por sentado que estos existen per se.

La argumentación referida por la Corte también incurre en el error primero, pues establece una posibilidad valorativa de acuerdo con un cambio en las circunstancias históricas de la sociedad. El cambio de jurisprudencia se fundamenta argumentando simplemente un cambio en las circunstancias sociales sin que medie una construcción del valor.

Otro error identificado en la narrativa de la Corte es el que identifica el valor con ciertos rasgos naturales de la existencia. En este sentido, el argumento central enfatiza la calidad de ser humano como fin en sí mismo sin que sea justificada racionalmente tal connotación.

La constatación de estos errores, siguiendo la línea de razonamiento expuesta desde el principio del artículo, sumada a la simple comparación con los conceptos objetivistas, conduce a concluir que la metaética de la Corte Suprema de Justicia Argentina es de la estirpe objetivista. Para esta institución, los valores existen por sí mismos, pues no brindan razones que justifiquen su existencia y aplicación.

\section{REFERENCIAS}

Edgar Bodenheimmer. Teoría Del DeRecho. 7.a ed. Trad. Vicente Herrero. Págs. 145-149. Fondo de Cultura Económico. (1979).

Eduardo Barbarosch. TEORÍAs DE LA JUSTICIA Y LA METAÉTIca contemporánea. Facultad de Derecho de la UBA y La Ley. (2007).

Hans Kelsen. Teoría pura del derecho. 18.a ed. Trad. Moisés Nilve. Editorial UBA. (1982).

Werner Goldschmidt. InTRoducción FILOsófica AL DeRECHo. 7.a ed. Lexis Nexis. (2005). 